Hara, N., \& Shachaf, P. (2008). Online peace movement organizations: A comparative analysis. In: I. Chen \& T. Kidd (Eds.). Social information technology: Connection society and cultural issues. Hershey , PA : Idea Group. pp. 52-67.

\title{
A comparative analysis of online peace movement organizations
}

\author{
*Noriko Hara \\ Indiana University, Bloomington \\ nhara@indiana.edu \\ (812) 855-1490 \\ Pnina Shachaf \\ Indiana University, Bloomington \\ shachaf@indiana.edu \\ (812) 856-1587
}

School of Library and Information Science, 1320 E Tenth Street, LI025, Indiana University, Bloomington, IN 47405-3907* Corresponding author

To be published in I. Chen \& T. Kidd (Eds.). Social information technology: Connection society and cultural issues. Hershey, PA: Idea Group.

\begin{abstract}
The use of the Internet for civic engagement by the general public is becoming increasingly prevalent, yet research in this area is still sparse. More studies are particularly needed in the area of cross-cultural comparisons of online social movements or online peace movement organizations (PMOs). While it is possible that PMOs in diverse cultures differ in their collective action frames, it is unclear whether PMOs use collective action frames and, if so, how differently they are used. This paper describes a comparative study that examined websites of PMOs in Japan and Israel. Collective action frame is used as a theoretical framework to analyze seventeen websites, identifying the similarities and differences in the ways that online PMOs frame their activities. The findings indicate that these organizations employed various strategies to develop resonance, highlighting the importance of cultural resonance in framing online PMOs in different countries.
\end{abstract}

\section{Introduction}

The Internet has long been recognized for its ability to reduce initial barriers to transnational collective action, thus making it easier for the general public to participate (e.g., McCaughey \& Ayers, 2003). "Digital communication networks" have expanded mobilization of movements across cultural and national levels (Bennett, 2003). The advancement of Information and Communication Technologies (ICTs) has become an indispensable part of daily life in the United States (Hoffman, Novak, \& Venkatesh, 2004) and other developed countries. The number of Internet users has increased from 30 million in 1995 to 900 million in 2004 (Nardi, Schiano, \& Gumbrecht, 2004). In particular, the Internet has contributed to our field of study by facilitating collective action through resource distribution and the organization of forces (McCaughey \& Ayers, 2003; Bennett, 2003).

Collective action involves organizing oppressed populations for the purpose of making positive changes in their social situations (Gamson, 1975; Tarrow, 1998). One collective action against the war in Iraq in 2003 was organized through the medium of the Internet. On February 15, 2003, peace demonstrations against the Iraq war were organized throughout the world, involving approximately ten million people (Boyd, 2003). Apparently the Internet played a pivotal role in facilitating the mobilization of this massive social action (Lee, 2003; Packer, 2003). 
Internet use for civic engagement has been gradually increasing and, although social and political scientists have widely studied social movements for a number of years, the role of technologies to support the activities of these movements has rarely been investigated. Historically, technology has constructively influenced social movements, perhaps most famously in the use of the printing press by European social movements in the late eighteenth century (Tarrow, 1998). With the press, social movement organizers were able to widely distribute their ideas and better coordinate their activities. More recently, telephones, direct mailings, fax machines, and e-mails have commonly been used to disseminate information as well as mobilize critical mass (McCarthy \& Zald, 1977; Porta \& Diani, 1999). In a similar vein, ICTs have had a major impact on numerous recent social movements. While participation in social movements has traditionally been limited to so-called activists, today general citizens who may not consider themselves activists are participating in online civic engagement (e.g. Looney, 2004). Because of the wide use of the Internet, social movements are finding a way to reach the general public. As a result, it has become important for social movements to strategically frame their actions, in order to appeal to a wider audience.

Studies on the use of the Internet by social movements mostly examine a case or a single country. These studies have focused on feminist activists (Ayers, 2003); democratization activists in Burma (Danitz \& Strobel, 1999) and Mexico, i.e., the Zapatista Movement (Arquilla \& Ronfeldt, 2001); and environmental activists (Galusky, 2003), emphasizing the important role that ICTs play within their movements. In the case of Burma, the ICT influences were indispensable at multiple levels: connecting freedom fighters all over the world, disseminating information quickly and cheaply, and gaining international support to organize boycotts and sanctions. While deep understanding of ICT use in a particular country is important, generalizations of findings from one country to another should be made with caution. Still, not a single study reports an international analysis of collective action frame in online activism. Our study addresses this disparity and tries to identify the similarities and differences among countries through a crosscultural comparative analysis of peace movement organizations' (PMOs) websites. This study describes how online PMOs who promote a similar cause, namely peace, in Japan and Israel differ from each other in framing their activities to encourage participation from the general public. Through the analysis of websites in these two countries, this study provides insight into how cultural diversity influences the way online PMOs frame their activities. Peace movements were deemed particularly appropriate for this international comparison of social movements as they promote a globally shared cause.

\section{Background: Collective action frame}

In this comparative analysis, "collective action frame" is used to understand how the Internet was utilized to support PMOs in framing their activities to promote participation by the general public. Collective action frame is a theoretical framework that explains how social movement organizations facilitate developing collective cognitive frames to justify their activities and encourage wider participation. Collective action frames have been widely used to examine traditional (face-to-face) social movements. Benford and Snow (2000) define collective action frames as "action-oriented sets of beliefs and meanings that inspire and legitimate the activities and campaigns of a social movement organization" (p. 614). Their review of the literature on framing processes and social movements indicate this theoretical framework has been increasingly used over the years in studies of social movements. 
Using Oliver and Johnston's (2000) characteristics of frame analysis, we focused on collective frames in this study and on the representations of frames. Oliver and Johnston define frames in terms of how individuals perceive phenomena, i.e., as "individual cognitive structures" (p.41). As such, these frames serve as the building blocks for the other three characteristics of the frame analysis. Though individually developed, frames, when united, have the potential to develop into resonated entities, eventually becoming collective frames. These collective frames become pivotal elements in supporting collective action and can be observed by examining representations of frames. For example, PMOs websites are snapshots of representations of collective action frames. While frames can be analyzed as a snapshot of a stable cognitive framework, some prior studies have examined processes of developing frames (e.g., see the discussion of frame alight process examined by Snow, Rochford, Worden, \& Benford, (1986) below). In this sense, structured frames and framing processes should be distinguished from each other, the former serving as the primary focus in this study. Collective action frames do not emerge spontaneously but rather require processes of integration whereby individual frames of a movement are organized into a coherent and collective frame. Such integration enables collective action. "Frame alignment processes" are explained by Snow, et al. (1986) as the processes necessary to link individual interpretation of a movement to the frame provided by social movement organizations. They further elaborate and explain four types of frame alignment processes: frame bridging, frame amplification, frame extension, and frame transformation. Snow et al. (1986) describe frame bridging as making a link between "two or more ideologically congruent but structurally unconnected frames regarding a particular issue or problem” (p. 467) while frame bridging is primarily executed by disseminating information through social networks, mass media, and other means. Frame amplification refers to strengthening a frame that supports a certain issue. Frame extension describes efforts to expand an existing frame to increase the number of supporters and participants. Finally, frame transformation occurs when the original framing is a misfit, which requires social movement organizations to readjust their frames. Snow et al's framework for frame alignment process is useful when analyzing PMO websites.

Snow et al. (1986) suggest that one of the four characteristics, frame bridging, is best facilitated through new technologies, allowing social movement organizations to promote their own agendas. Hara and Estrada (2005), like other researchers (e.g., Hoffman, et al., 2004; Kahn \& Kellner, 2004), have shown how information and communication technologies (ICTs), such as e-mail, websites, and blogs, have helped mobilize, not only hardcore activists, but socially-conscious lay people. In the past, social movement organizations had limited means to promote their activities and ideologies, relying for the most part on the news media. The framing of the social movement organizations' activities by the news media was sometimes inconsistent with their own (see e.g., Gamson, Croteau, Hoynes, \& Sasson, 1992). In fact, Alemeida and Lichbach (2003) examined the reporting of worldwide protests for the World Trade Organization and found that activists' own websites had the most accumulative reporting of the protest events. Even the international news organizations did not extensively report on the protest events. The news organizations tend to cover sensational (e.g., violent and large) protests more than civil and peaceful protest events (Oliver \& Maney, 2000). With the use of ICTs, social movement organizations now have a better way to reach the general public and frame their movements to their advantage. 
According to Benford and Snow (2000), collective action frames can best be differentiated from each other by observing how much resonance a movement can produce between a social movement organization and individuals. In their reading of resonance, defined as an act of producing an agreement with a presented frame, Benford and Snow have identified two factors influencing the degree of resonance: "credibility of the proffered frame and its relative salience" (p. 619). Credibility of the frame can be affected by consistency of messages sent by the social movement organization, the reality of the frame (whether it makes sense to the audiences), and persuasiveness of the frame (for example, strong leadership could provide credibility to a movement). Relative salience to the audience can be influenced by the significance of the issues presented by social movement organizations, the relevance of the presented frame, and the extent of cultural resonance produced by the presented frame.

Cultural resonance has the potential to enhance or inhibit the persuasiveness of social movements in general and PMOs in particular. Cultural resonance is an incidence within which movement organizers develop a frame that is sensitive to cultural components, which, in turn, might influence the mobilization of movements, such as in the case of a student movement in Tiananmen Square of China (Zuo \& Benford, 1995). This student movement originally tried to frame the movement to appeal to the Chinese government - it was only after a lack of governmental response that they changed their framing of activities to increase frame alignment with ordinary citizens, using three core Chinese traditions (Confucianism, communism, and nationalism). For example, the movement used a hunger strike as a tactic, which appealed to Chinese citizens because it aligned with the traditional Confucianist tenet of self-sacrifice. Further, Porta and Diani (1999) also emphasize the importance of culture in social movement research when stating, "culture provides the cognitive apparatus which people need to orient themselves in the world" (p. 68). Thus, different framing is necessary for people in different cultures. Though "peace" is often viewed as universally desirable concept, interpretations of it vary greatly across different cultures. If the Eastern idea of peace connotes harmony, achieved internally as a state of mind, the Western idea of peace centers on victory, usually achieved externally through war (Ishida, 1969). By recognizing the inherent cultural differences in the meaning of peace, PMOs are more likely to produce cultural resonance with their frames; otherwise, they will not receive adequate support from the general public in their own countries. ICTs allow social movement organizations to have the control and legitimacy over content disseminated through the Internet (Garrett, 2006). As country specific cases were investigated, this paper presents a cross-cultural analysis of PMOs, illuminating the importance of cultural resonance in collective action frames.

\section{Research methods}

In order to ascertain how PMOs in Japan and Israel utilize the Internet for their activities, a comparative content analysis of the PMOs' websites has been applied. Content analysis of websites is a standard method through which to understand online activities, and other studies of online activisms, such as environmental advocacy (Sehmel, 2004), have used the method. Analysis of traditional social movements' collective action frame is rather difficult as activists do not advertise their framing to the general public, making it necessary for researchers to conduct interviews with these activists to identify and analyze their collective action frame (c.f. Snow, Rochford, Worden, \& Benford, 1986). Websites provide useful representations of frames for researchers when analyzing how PMOs frame their activities. 


\section{Data collection}

The study involved a comparative analysis of PMOs' websites from two countries that addressed the Middle East conflict in 2004. Japan and Israel were selected because both countries represent rare democracies in their geographical areas respectively; each of these two countries is the only democracy on their continent (Salter, 2003). In addition, because most of the studies on social movements have tended to focus on Western countries (Lee, 2003), analyzing Eastern countries is helpful in gaining a different perspective.

Because we could not find lists of PMO organizations in these two countries, the PMO website sample was based on searching Google and country specific webdirectories. We searched both Google.com and Google in each of the two countries: google.co.il for Israel and google.co.jp for Japan, using the term "peace" in Hebrew and Japanese, respectively. In addition, we examined web directories in the two countries and used a pearl growing searching technique, which involved following the external links that each of the PMO's websites provided. All in all, the sample included seventeen websites: six Israeli websites and eleven Japanese websites. A complete list of websites is presented in the Appendix.

The inclusion criteria for PMOs in this study were: (1) PMOs websites addressing the Middle East conflict (broadly-defined); and (2) PMOs websites use of country specific formal language on their website (Hebrew for Israel or Japanese for Japan). Unlike other studies that utilized comparative analysis of websites in several countries (Cyr \& Trevor-Smith, 2004), we found that a websites' URL could not serve as an indication of country specific PMOs. Cyr and Trevor-Smith (2004) analyzed governmental websites from Germany, the US, and Japan; in their study, these URLs were country specific. This method was not applicable to our study because PMOs are non-governmental grassroots organizations that use URLs which do not necessarily indicate the country of origin. Thus, a websites' URL could not serve as an indication of country specific PMOs. Our resolution was to identify country-specific PMOs' websites through the use of the formal language of the country. The chosen PMOs have created websites in Hebrew for Israel and Japanese for Japan. English websites of Israeli or Japanese PMOs were not included in our sample even when, for example, they were using Israeli URLs, and had contact information in Israel.

\section{Data analysis}

Analysis of data began as the data were collected. After comparative content analysis was conducted on one PMO website from each country, a coding schema was developed, and then applied to other websites. We deployed an open coding approach while collective action frame was used as a guide to develop the schema. As the coding evolved, additional codes emerged and were later integrated into the coding schema. We followed Westbrook’s (1994) suggestion that "whatever theory or working hypothesis eventually develops must grow naturally from the data analysis rather than standing to the side as an a priori statement that the data will find to be accurate or wanting." (p.245). Thus the analysis was grounded in the data, and we identified emerging themes salient in collective action frame.

\section{Limitations}

The major limitation of this study is its sample size, which only focused on PMO websites in two countries, Israel and Japan. Transferability of these findings to other countries in the world must proceed tenuously. Future studies need to expand the sample size.

\section{Findings and discussion}


The nature and framing of PMO’s activities could appeal to the general public around the globe, not least as the concept of peace is universal. For that reason, the Internet could facilitate globalization of PMOs. The findings of the comparative analysis of PMOs illustrate "glocalization," or the co-existence of globalization and localization [Robertson, 2001] and not globalization alone. This process of glocalization is probably a result of the efforts of the activists to develop and emphasize "cultural resonance" (Benford \& Snow, 2000) to fit a local population (of a specific country). The findings illustrate how the process of framing peace to increase cultural resonance changes depending on local cultures, languages, and the sociopolitical context in Japan and Israel. The findings are described along five themes, which emerged from the comparative analysis and the coding scheme: 1) scope of peace, 2) language use, 3) influence of culture and communication patterns, 4) leadership, and 5) online collective action. The first four focus on glocalization and the framing processes that aim to increase cultural resonance, while the fifth emphasizes the collective action frame in this socio-political context and describes how the framing of PMOs facilitates the promotion of PMO's collective action.

\section{1) Scope of peace}

One of the most prominent aspects of framing peace to increase cultural resonance is accomplished through the PMOs' presentation reflecting the local perspective on peace. On the one hand, the peace scope in Israel focused on the Israeli-Palestinian conflict and involved almost no references to the war in Iraq. This is an extremely domestic approach to peace in the Middle East. In Japan, on the other hand, the scope of peace involved not only domestic peace but also a concern over the war in Iraq as well as information on the Israeli-Palestinian conflict. On the Japanese websites, the common domestic peace interests were a protest against U.S. military bases in Okinawa and the debate over the ninth clause in the Japanese constitution, a section established after World War II that prohibits Japan from using armed force to resolve conflicts. However many different views exist, so long as the clause is in place the Japanese government does not operate an official army. However, the Japanese websites did not focus solely on their domestic peace issues but also provided peace information about conflicts in other countries across the globe. One of the most common issues discussed on Japanese websites related to the Iraq war. The Israeli-Palestinian conflict, viewed primarily as a Middle Eastern concern, appeared to a far lesser extent on these websites. The Japanese perspective on peace seemed to reflect a global approach, as compared with the Israeli approach that focused on a solution to a local conflict. In both countries, however, this was an example of glocalizing peace.

To better understand modern peace movements in Japan and Israel, different perspectives on "peace" among various cultures were examined (Ishida, 1969). Israel is influenced by the Judea - Christian perception of peace (Shalom or Brit-Shalom) while Japan is influenced by Confucian ethics (Heiwa). On the one hand, peace in Israel is conceptualized as negotiations within relationships, which need to be maintained over time. Peace, according to this approach, is achieved externally through war and involves the desire for justice. A militant, violent, and at times illegal attitude of Gush Shalom in Israel was an extreme interpretation of peace under the Judea-Christian ethics. On the other hand, peace in Japan is conceptualized as a tranquil state of mind, which means harmony and adaptation to social order. This internal concept of peace involves interrelated notions of aesthetics and harmony in which social order and individual emotions are intertwined (based on the tradition of Shinto - where aesthetic factors were dominant). The Confucian influence on the 9Love website had a non-conflict and aesthetic, holistic approach. These disparate perceptions of peace greatly influenced the way each country framed their PMOs activities to gain cultural resonance. 


\section{2) Language use}

The second aspect of framing peace to appeal to local audiences was to use languages. PMOs develop better cultural resonance by customizing the style of verbal messages for the local masses and by using local languages. This framing aspect was evident in two ways: (1) a dominant language used on the majority of a website. For example, on most of the Japanese websites, Japanese was more dominant than English; (2) a use of at least four different languages (Hebrew, Arabic, English, and Russian) in most of the Israeli websites. The use of four languages among Israeli websites reflected the diversity of languages used by the linguistically and culturally diverse Israeli population. However, in many of the Israeli websites, Hebrew was the most prominent language used. It should be stressed that the dominance of languages we found on the websites corresponds with the formal and foreign languages used in the two countries (CIA, 2004). For Japan, the CIA's World Factbook lists Japanese as the sole formal language used in Japan, whereas, for Israel, it lists Hebrew as only one of several official languages. Arabic was listed for Israel as the second formal language because it is officially used by the Arab minority, and English was listed as the most frequently used foreign language. Russian is used extensively in Israel as a result of a mass immigration from Russia to Israel during the last decade.

Moreover, we found additional languages (aside from the formal languages) used on the websites in both Japan and Israel. In Japan, only five out of the eleven Japanese websites involved 1-2 additional languages. For example, the 9Love website was in Japanese only. This preponderance of Japanese-only sites was probably because of the website's content, as it focused on framing the scope of peace in domestic terms, such as the ninth clause of the Japanese constitution. Another reason for the use of one language (Japanese) on these websites was the homogeneous nature of the Japanese population, which overwhelmingly speaks Japanese. This website (9Love) exhibited other strong local features, influenced by Confucianism, including an emphasis on aesthetics and on references to other meanings of the number nine in Japanese culture. In the World Peace Now website (Japanese website), while English words were used on the Japanese pages, a shorter version of the website was provided in English. (In fact, the link to the English version was not hosted in the World Peace Now website.) The use of English pages probably reflected the site's global perspective frame, which aimed to achieve international visibility. Another Japanese website, Peace Boat, provided equal amounts of information in English and Japanese, making it the least localized website among the Japanese websites. This was in accordance with Peace Boat's conception of peace, which was more global in nature than most of the Japanese peace sites. Finally, the Peace Depot (Japanese) website used three languages: English, Japanese, and Korean, which represented the maximum number of language used on any of the Japanese websites. It becomes easier to understand the increased incidence of Korean pages offered when we keep in mind that some members of the advisory board were Koreans. In Israel the use of multiple languages on PMOs' websites was more prevalent, as these sites use Hebrew, Arabic, English, and Russian. The first three were mentioned in the CIA World Factbook (CIA, 2004) as languages used frequently in Israel. Russian was used on these websites due to a large Russian immigration group in Israel, whose native language is Russian and who constitute about $25 \%$ of the Jewish population in Israel today. Thus, despite the fact that Russian is not an official language in Israel, it is, nonetheless, commonly used there. Furthermore, while Russian immigrants were traditionally considered to be unsupportive of the "left wing" and of the peace movements in the past, peace movements are now eager to attract immigrants of Russian descent. For instance, "Gush Shalom Seeks Dialog with the Russians" framed the campaign to target this particular group (see: http://www.gushshalom.org/actions/action19-9-2004.html). 
The use of four languages on the Israeli peace movements' websites was an example of the effort to create cultural resonance. Still, the use of eleven languages on the Neve Shalom (Israeli) website (most likely for public relations) provided the most global approach in terms of language use on websites in Israel or Japan. The use of multiple languages reflected Neve Shalom's idea of multicultural coexistence, practiced in daily life. Consequently, their use of multiple languages reflected, in contrast to the other peace movements, a desire to achieve global support for their actions and beliefs, rather than merely communicate with large local groups.

PMOs used languages on their websites to frame the boundary of their activities and the populations they reach. The use of a specific language, which was spoken in only one country, limited and defined participation in the organization's activities. For example, to participate in the discussions and activities of the 9Love website, the participants needed to understand Japanese. While none of the Israeli websites presented information exclusively in Hebrew, most of the Japanese websites presented information solely in Japanese.

In summary, local languages were primarily used for cultural resonance purposes and in order to frame group identity through excluding others. The use of multiple languages on PMO websites indicated frame extension in both countries to increase supporters. Israeli websites used frame extension through multiple language use more often than their Japanese counterparts. At the same time, the collective action frames in both countries did not target everyone who would like to promote peace, but rather only those who were able to understand the language(s). The choice of the languages used by the PMOs on their websites enabled or excluded potential global participation. In this respect, we can contend that the Japanese websites were the more exclusive, and thus more localized than the Israeli websites, although in both countries PMOs' website were glocalized.

\section{3) Influence of culture and communication patterns}

Another difference in attempts to increase cultural resonance was evident when analyzing culturally defined communication patterns. According to Hall's (1984) dichotomy, if Japan is more representative of what has been termed a "high context culture,” Israel stands for "a low context culture.” A high context culture focuses on processes, while a low context culture focuses on the results. In a high context culture, the focus is on the group, while in a low context culture, the focus is on the individual. In a high context culture, people communicate indirectly and rely on non-verbal messages. In contrast, in a low context culture, people communicate directly and do not rely heavily on non-verbal messages. If high context cultures conceive of communication as art where knowledge is embedded in the context, in low context cultures, communication is information exchange where knowledge is not context dependant. These differences in communication style between the two countries are evident on the PMOs websites. When PMOs frame and justify their activities, they tend to follow culturally-dependent communication styles.

Thus a third cultural resonance aspect involves the influence of culture on communication and organizational dynamics. This was palpable, for example, in the case of the indirect style of communication (Gudykunst \& Ting-Toomey, 1988) of the Japanese website, reflecting the Japanese high context culture (Hall, 1984). The Japanese PMOs did not clearly state their mission or goals on their websites. They did not directly try to influence the masses by justifying their support of peace actions. These goals and missions of the PMOs appeared to be well understood by the masses in Japan, based on shared understanding that did not need to be verbally communicated. The Japanese websites, even when written in English, presented the same indirect style of its high context culture. Unlike the Japanese PMOs, the Israeli PMOs did not assume any shared context. Thus, they clearly stated their mission and goals on their websites and made additional efforts to legitimize their actions by using photos of the PMOs' leaders. This direct communication style, reflecting their low context culture, was apparent in all the languages of each Israeli website. 


\section{4) Leadership}

One of the factors influencing "frame resonance" is related to the empirical credibility of how a collective action frame is presented to its audiences (Benford \& Snow, 2000). This empirical credibility is partially achieved through leadership. For Israeli PMOs, there was always a leader or two who founded the organization and provided empirical credibility for the collective action frame. To firmly entrench their peace movement, Israeli PMOs used leaders with political or military credentials, which provided credibility for the organization's existence and its activities. All the Israeli PMOs in this study, as evident from their websites, were leader-centered. While the Israeli websites centralized around their leaders, it appeared that the majority of the Japanese websites were "leaderless resistance.” The Japanese PMO websites we analyzed did not explicitly articulate the identities of their leaders. Garfinkel (2003) noted, "Leaderless Resistance is a technique for fighting an incumbent government using selforganizing clandestine cells.” Garfinkel contended that this type of resistance was observed in recent animal rights and environmental movements. Levin (2002) also argued that white supremacist organizations become leaderless resistant, suggesting its increased prevalence as a predominant form of social movements. While the Japanese PMO websites' leadership was more structured than this leaderless resistance concept, Japanese PMOs seemed to use a consensus-based leadership style. Based on the Japanese culture, it was speculated that the leaderless nature of Japanese PMOs was a default of collective action, which increase cultural resonance amongst the Japanese population. As a high context culture, Japanese sites tend to value group interests over individual (Hofstede, 1991). Nine of the Japanese peace websites did not mention individual names of leaders or organizers. World Peace Now was a rather extreme example of leaderless PMOs. Under "Contact Us," they did not provide physical address, names of activists, or their email addresses, but listed a general e-mail address and phone numbers for participating organizations. The websites did not explicitly identify their organizers or the activists involved in their PMOs activities.

\section{5) Online collective actions}

Although the PMOs we analyzed did not exist solely online, their online actions represented the framing of PMOs' activities, which reinforce their support for collective action. While participation in social organization activities has traditionally been offline, we focused our attention on PMOs participants' online actions and identified several distinct actions that have been appropriated by the use of the Internet. These online actions ranged in participation level from passive involvement, such as participants browsing through the information available online (e.g., World Peace Now), to more active involvement, such as participants signing a petition (e.g., Hamifkad Haleumi) or participating in online discussion forums (e.g., Gush Shalom). All of the PMOs also enabled interested parties to donate online, and most of them enabled online visitors to become more active members. These online actions were global ways of promoting collective action online; yet, Israeli websites provided a wider variety of online actions than did the Japanese websites. 
This diversity of actions perhaps reflected the larger tendency of Israelis to share their opinions online. In general, Israelis tend to be verbally involved in writing comments in political (and other) discussion forums. This tendency spills over into discussions of any article in the main daily and weekly online newspapers, such as Maariv (http://www.nrg.co.il/) and Yediot Aharonut (http://www.ynet.co.il/). For example, an article on Arafat during the days he was in a coma attracted more than 500 posts from readers on the Maariv online website. Similarly, Gush Shalom had a very active discussion forum in Hebrew about the same topic. Although the English and Arabic versions of the Gush Shalom website provided the infrastructure for discussion forums, this type of online discussion forum was not used in these other languages. This participation could stem from culturally embedded behaviors. We have not identified a similar level of political involvement from readers of online newspapers in English, Japanese, or Arabic. However, it is worthwhile to note that before the U.S. started the Iraq war, MoveOn.org was involved in the anti Iraq war movement, in which they used similar strategies, such as online petitions and discussion forums (Hara \& Estrada, 2005).

In the analysis of online actions, one should make a distinction between two levels of argument about online actions: the infrastructure for online activity and the actual online actions. At the infrastructure level, it is clear that there was no infrastructure for discussion forums on most of the PMO websites in our sample. The only two websites that provided this infrastructure were Israeli sites, Neve Shalom and Gush Shalom. Yet, it was only on the Gush shalom's discussion forum that active discussions were found, mostly in Hebrew (the infrastructure also supports English and Arabic). On the Neve Shalom discussion forum only a few messages were submitted. The infrastructure was more like a bulletin board than a forum, which did not promote engaging in discussion.

Another unique type of online action with respect to Israeli websites was the option to sign a petition. This was probably unique to the particular goals of this PMO and the types of actions they were focusing on; therefore this type of online action may not be useful for other PMOs.

A third online action available exclusively on one particular Israeli website, Neve Shalom, was the option to post a message to a guest book- just like a physical paper guest book for visitors in the actual Neve Shalom village.

Many of the PMOs' websites in both countries had information about donations on their first page and an option for subscribing to their e-mail list. Similarly, another online activity across all the websites was the reporting of current events planned by the organizations. As mentioned earlier, this was an advantage provided by the Internet to these organizations. PMOs can control the content on their websites, frame their own collective action, and reach a wider audience. These websites were updated at least once a week and sometimes more frequently. This reflects the nature of the Internet, a medium that requires constant updates; otherwise, users will not be loyal to that particular website (Farkas \& Farkas, 2002). These websites did not appear to substitute for existing offline peace movements' actions. The online actions took place in addition to the traditional peace movement actions: demonstrations, rallies, talks, and petitions. PMOs' websites, like other non-political online activities facilitated through the Internet, enabled additional non-traditional actions, such as geographically-dispersed group discussions and information dissemination to larger audiences in shorter periods of time. 


\section{Conclusions and Future Trends}

The PMOs' common purposes, which we found and analyzed, include massive mobilization, connecting people, widely disseminating information, and advocating their perspectives through collective action frames. These actions, evident on PMOs websites in these two countries, are similar to other grassroots organizations that use the Internet. For example, it is widely reported that mobilization of protests for the World Trade Organization was facilitated by the Internet (e.g., Almeida \& Lichbach, 2003; Vegh, 2003). The Internet helps connect people who have similar mindsets (e.g., Danitz \& Strobel, 1999; Levin, 2002; Agre, 2002) and helps grassroots organizations disseminate information with lower transaction costs (e.g., Bennett, 2003, Martinez-Torres, 2001). Previous research on online social movements has not explicitly addressed the notion of collective action frames in relation to cultural resonance and ignores the significant role culture plays in framing collective action. In this study we examined how PMOs, as one type of social movement, advocate their perspectives by using collective action frames in two disparate contexts.

Specifically, this paper described a comparative study that examined PMOs' websites in two non-western countries (Japan and Israel). Utilizing a framework of collective action frames to analyze seventeen websites, the following themes emerged: scope of peace, language use, culture and communication, leadership, and online actions. Our findings show that these websites exhibit indicators for strong cultural resonance, or "glocalization,” to frame a universal concept, peace, into their own cultural contexts. We also identified various communication patterns on the websites as well as online actions that underline the importance of collective action frame in increasing cultural resonance. It was apparent that these PMO websites carefully framed their motives and activities to align with cultural values and norms. This study demonstrates how culture influences collective action frames in the context of two countries. Further studies need to increase the number of countries used for analysis. Moreover, this study found that the Internet not only facilitates frame bridging, as others have previously claimed, but also supports frame extension for use of multiple languages on the examined websites.

As to whether online activism will continue to be more pervasive, there can be little question, yet the study of online activism is still in its infancy. We hope this study will serve as a starting point for future studies in this area.

\section{Future Research Directions}

Although many interesting cases examining the role that ICTs play in mobilizing grassroots activities have emerged in recent years, research in this area appears to be lagging behind, involving only a limited number of case studies, e.g., the anti-WTO movement (e.g., Kahn \& Kellner, 2004), Zapatista movement (e.g., Arquilla and Ronfeldt, 2001), and Indymedia (e.g., Kidd, 2003). So far, these case studies have focused attention mainly on Internet use without investigating mobile devices and other technologies which, in many cases, are more extensively utilized by social movements, such as the SARS crisis in China in 2003 (Castells, Fernandez-Ardevol, Qiu, \& Sey, 2007) and April 10 Mobilization in 2006 by undocumented immigrants in the U.S.. These kinds of studies have the potential to enhance the existing theoretical frameworks with novel perspectives. 
Additionally, a range of other studies may shed further light on the diverse strategies used by ICT-driven movements, e.g., frame alignment processes that these movements undergo. Currently theoretical frameworks of ICT-driven mobilization are scarce. Some researchers, such as Bimber, Flanagin, and Stohl (2005) and Bennett (2003), attempt to address this research cavity. However, a disconnect between the traditional theories about social movements and the rising ICT-driven social movements is evident. As Garrett (2006) suggests, it would be fruitful to combine multiple methods to understand the ICT-driven phenomena. Once more case studies are available, it may facilitate the development and synthesis of various theoretical frameworks.

\section{Terms and Definitions}

Collective action: An action that a group of people engage in to pursue a common goal.

Collective action frame: A theoretical framework that explains how social movement organizations facilitate developing collective cognitive frame $s$ to justify their activities.

Cultural resonance: An act of producing meaning to a specific culture.

Frame: A cognitive structure that shapes how an individual perceive phenomena.

Social Movement: Groups of individuals and/or organizations working to achieve a social change based on particular political or social issues.

Peace Movement Organization: An organization that was established to promote peace as social action.

\section{References}

Agre, PE. (2002). Cyberspace as American culture. Science as Culture. 11(2), 171-189.

Almeida, PD., \& Lichbach, MI. (2003). To the Internet, From the Internet: Comparative media coverage of transnational protests. Mobilization: An International Journal. 8(3), 249-272.

Arquilla, J., \& Ronfeldt, D. (2001). Emergence and influence of the Zapatista social netwar. In D. Ronfeldt \& J. Arquilla (Eds.). Networks and netwars: The future of terror, crime, and militancy (pp. 171-199). Santa Monica, CA: RAND.

Ayers, MD. (2003). Comparing collective identity in online and offline feminist activists. In M. McCaughey \& MD., Ayers (Eds.), Cyberactivism: Online activism in theory and practice (pp.145-164). New York: Routledge.

Benford, RD., \& Snow, DA. (2000). Framing processes and social movements: An overview and assessment. Annual Review of Sociology. 26, 611-639. Bennett, WL. (2003). Communicating global activism: Strengths and vulnerabilities of networked politics. Information, Communication \& Society. 6(2), 143-168.

Boyd, A. (2003, August 4). The web requires the movement. The Nation. Retrieved October 31, 2006 from http://www.thenation.com/doc.mhtml?i=20030804\&c=1\&s=boyd

Castells, M., Fernandez-Ardevol, M., Qiu, J. L., \& Sey, A. (2007). Mobile communication and society: A global perspective. Cambridge, MA: MIT Press. CIA, (2004). The World FactBook, Retrieved October 31, 2006 from https:/www.cia.gov/cia/publications/factbook/index.html Cyr, D., \& Trevor-Smith, H. (2004). Localization of web design: An empirical comparison of German, Japanese, and United States Web site characteristics. 
Journal of the American Society for Information Science \& Technology. 55(13), 1199-1208.

Danitz, T., \& Strobel, WP. (1999). The Internet's impact on activism: The case of Burma. Studies in Conflict and Terrorism. 22, 257-269.

Farkas, DK., \& Farkas, JB. (2002). Principles of web design. New York, NY: The Allyn \& Bacon.

Galusky, W. (2003). Identifying with information: Citizen empowerment, the Internet, and the environmental anti-toxins movement. In M. McCaughey \& M. D. Ayers (Eds.), Cyberactivism: Online activism in theory and practice (pp. 185-205). New York: Routledge.

Gamson, W. (1975). The strategy of social protest (2nd ed.). Belmont, CA: Wadsworth Publishing.

Gamson, WA., Croteau, D., Hoynes, W., \& Sasson, T. (1992). Media images and the social construction of reality. Annual Reviews of Sociology. 18, 373-393.

Garrett, RK. (2006). Protest in an information society: A review of literature on social movements and new ICTs. Information, Communication \& Society. 9(2), 202-224.

Garfinkel, SL. (2003). Leaderless resistance today. First Monday. 8(3), Retrieved October 31, 2006 from http://www.firstmonday.dk/issues/issue8_3/garfinkel/index.html

Gudykunst, WB., \& Ting-Toomey, S. (1988). Culture and interpersonal communication. Newbury Park, CA: Sage.

Hall, ET. (1984). The dance of life: The other dimension of time. Garden City, N.Y., Anchor Press/Doubleday.

Hara, N., \& Estrada, Z. (2005). An approach to analyse grassroots mobilization online: A case study. Journal of Information Science. 31(6), 503-514.

Hoffman, DL., Novak, TP., Venkatesh, A. (2004). Has the Internet become indispensable? Communication of the ACM. 47(7), 37-42.

Hofstede, G. (1991). Cultures and Organizations: Software of the Mind. London: McGraw-Hill U.K.

Ishida, T. (1969). Beyond traditional concepts of peace in different cultures. Journal of Peace Research. 6(2), 133-145.

Kahn, R., \& Kellner, D. (2004). New media and internet activism: From the 'Battle of Seattle' to blogging. New Media and Society. 6(1), 87-95.

Kidd, D. (2003). Indymedia.org: A new communications commons. In M. McCaughey \&

M. D. Ayers (Eds.), Cyberactivism: Online activism in theory and practice. London. Routledge. Lee, J. (February 23, 2003). Critical mass: How protesters mobilized so many and so nimbly. New York Times, WK 3. Levin, B. (2002). Cyberhate: A legal and historical analysis of extremists' use of computer networks in America. American Behavioral Scientists. 45(6), 958-988. Looney, S. (2004). Civic participation and the Internet. LBJ Journal of Public Affairs. 14, 49-61. Martinez-Torres, ME., (2001). Civil society, the internet, and the Zapatistas. Peace Review. 13(3), 347-355.

McCarthy, JD., \& Zald, MN. (1977). Resource mobilization and social movements: A partial theory, American Journal of Sociology. 82 (May), 1212-1239. 
McCaughey, M., \& Ayers, M.D. (Eds.) (2003). Cyberactivism: Online activism in theory and practice. New York: Routledge

Nardi, BA., Schiano, DJ., \& Gumbrecht, M. (2004). Blogging as social activity, or would you let 900 million people read your diary? Proceedings of the 2004 ACM conference on Computer Supported Cooperative Work, 222-231.

Oliver, PE., \& Johnston, H. (2000). What a good idea! Frames and ideologies in social movement research. Mobilization: An international journal. 5(1), 37-54.

Oliver, PE., \& Maney, GM. (2000). Political processes and local newspaper coverage of protest events: From selection bias to triadic interactions. American Journal of Sociology. 106 (2), 463-505.

Packer, G. (March 9, 2003). Smart-mobbing the war. Eli Pariser and other young antiwar organizers are the first to be using wired technologies as weapons. New York Times Magazine. Section 6, p. 46.

Porta, DD. \& Diani, M. (1999). Social movements: An introduction. Oxford: Blackwell Publishing.

Robertson, R. (2001). Comments on the "global triad" and "glocalization." Retrieved October 31, 2006 from http://www2.kokugakuin.ac.jp/ijcc/wp/global/15robertson.html

Salter, L. (2003). Democracy, new social movements, and the Internet: A Habermasian analysis. In McCaughey, M. \& Ayers, M. (Eds.), Cyberactivism: Online activism in theory and practice. New York, NY: Routledge.

Sehmel, H. (2004). How a small environmental group uses the web to inform and promote action: A content analysis. In A. Scharl (Ed.), Environmental online communication. London: Springer.

Snow, DA., Rochford, B., Worden, SK., \& Benford, RD. (1986). Frame alignment processes, micromobilization, and movement participation. American Sociological Review. 51(4), 464-481.

Tarrow, S. (1998). Power in movement: Social movements and contentious politics (2nd ed.). Cambridge: Cambridge University Press.

Vegh, S. (2003). Classifying forms of online activism: The case of cyberprotests against the World Bank. In M. McCaughey \& M. D. Ayers (Eds.), Cyberactivism: Online activism in theory and practice (pp. 71-95). New York: Routledge.

Westbrook, L. (1994). Qualitative research methods: A review of major stages, data analysis techniques, and quality controls. Library \& Information Science Research. 16(3), 241-254.

Zuo, J., \& Benford, RD. (1995). Mobilization processes and the 1989 Chinese democracy movement. The Sociological Quarterly. 36, 131-156.

\section{Additional Reading}

Bartlett, M. (2002). Paradigms of online peace activism. Peace Review: A Journal of Social Justice. 14(1), 121-128.

Benford, RD., \& Snow, DA. (2000). Framing processes and social movements: An overview and assessment. Annual Review of Sociology. 26, 611-639.

Bimber, B., Flanagin, AJ., \& Stohl, C. (2005). Reconceptualizing collective action in the contemporary media environment. Communication Theory. 15(4), 365-388.

Carty, V., \& Onyett, J. (2006). Protest, cyberactivism and new social movements: The 
reemergence of the peace movement post 9/11. Social Movement Studies. 5(3), 229-

249.

Castells, M., Fernandez-Ardevol, M., Qiu, J. L., \& Sey, A. (2007). Mobile

communication and society: A global perspective. Cambridge, MA: MIT Press.

Garrett, RK. (2006). Protest in an information society: A review of literature on social movements and new ICTs. Information, Communication \& Society. 9(2), 202-224.

Castells, M., Fernandez-Ardevol, M., Qiu, JL., \& Sey, A. (2007). Mobile communication and society: A global perspective. Cambridge, MA: MIT Press.

Diani, M. (2000). Social movement networks: Virtual and real. Information, Communication and Society. 3(3), 386-401.

Hands, J. (2006). Civil society, cosmopolitics and the net: The legacy of 15 February 2003. Information, Communication \& Society. 9(2), 225-243.

Hess, DJ. (2005). Technology- and product-oriented movements: Approximating social movement. Science, Technology \& Human Values. 30, 515-535.

Hunt, SA., \& Benford, RD. (1994). Identity talk in the peace and justice movement. Journal of Contemporary Ethnography. 22(4), 488-517.

Johnston, H., \& Klandermans, B. (1995). Social movements and culture. Minneapolis, MN: University of Minnesota Press.

McAdam, D., McCarthy, JD., \& Zald, MN. (1996). Introduction: Opportunities, mobilizing structures, and framing processes - toward a synthetic, comparative perspective on social movements. In McAdam, McCarthy and Zald (eds.) Comparative perspectives on social movements (1-20). New York: Cambridge University Press.

McCaughey, M., \& Ayers, M.D. (Eds.) (2003). Cyberactivism: Online activism in theory and practice. New York: Routledge.

Parvez, Z., \& Ahmed, P. (2006). Towards building an integrated perspective on edemocracy. Information, Communication \& Society. 9(5), 612-632.

Porta, DD., \& Diani M. (1999). Social movements: An introduction. Malden, MA: Blackwell.

Postmes, T., \& Brunsting, S. (2002). Collective action in the age of the Internet: Mass communication and online mobilization. Social Science Computer Review. 20(3), 290-301.

Ronfeldt, D. \& Arquilla, J. (2001). (Eds.). Networks and netwars: The future of terror, crime, and militancy. Santa Monica, CA: RAND. van de Donk, W., Loader, BD., Nihon, PG., \& Rucht, D. (2004). (Eds.), Cyberprotest: New media, citizens and social movements. London; New York: Routledge.

Westby, D. L. (2002). Strategic imperative, ideology, and frame. Mobilization. 7(3), 287304.

\section{Appendix: Websites analyzed for the study}

Japanese Web sites: World Peace Now http://www.worldpeacenow.jp/ Peace Boat http://www.peaceboat.org/index_j.html Bridge for peace http://www.bfpj.net/ Peace Depot http://www.peacedepot.org/ Japan Palestine Medical Association http://www1.ttcn.ne.jp/ jpma/ Campaign for Children of Palestine http://www32.ocn.ne.jp/ ccp/ Shion to no Kakehashi (Bridge to Zion) http://www.zion-jpn.or.jp 
Organization for Peace in Palestine http://www.palestine-forum.org Japan-Israel-Palestine Student Conference http://www.jipsc.org Women in Black http://www1.jca.apc.org/fem/wib/index2.html 9Love http://www.9love.org/

\section{Israeli Web sites:}

Gush Shalom (The Peace Bloc) http://www.gush-shalom.org Neve Shalom (Oasis for Peace) http://nswas.com/hebrew/ Hamifkad Haleumi (The People's Voice) www.mifkad.org.il Shalom Achshav (Peace Now) http://www.peacenow.org.il/site/he/homepage.asp Ken Leheskem -Yozmat Geneva(The Geneva Accord) PMO but not grassroots http://www.heskem.org.il/default.asp Kualitziat Nashim Leshalom (Coalition of Women for Peace) http://coalitionofwomen.org/home/hebrew 